\title{
The Impact of Cannabidiol on Psychiatric and Medical Conditions
}

\author{
Thersilla Oberbarnscheidt ${ }^{\mathrm{a}, \mathrm{c}}$, Norman S. Miller ${ }^{\mathrm{b}}$
}

\begin{abstract}
Cannabidiol (CBD) is a substance chemically derived from Cannabis sativa and discussed to be non-psychoactive. According to the FDA, marijuana is classified as a schedule I substance; however, hemp which is defined as extracts from marijuana including cannabinoids containing less than $0.3 \%$ tetrahydrocannabinol (THC), is excluded from that controlled substance act and available at local convenience stores in the US as it is seen as an herbal supplement. CBD is purported to be used for various medical and psychiatric conditions: depression, anxiety, post-traumatic stress disorder, Alzheimer's or other cognitive illnesses as well as pain. There is also a new trend to use CBD for the treatment of opioid use disorder. The one CBD product on the market that is FDA approved for the treatment of childhood epilepsy forms Dravet and Lennox-Gastaut syndromes is available under the name Epidiolex. There is a significant difference between this medication and the over-the-counter CBD products that contain very inconsistent strengths of $\mathrm{CBD}$, if they contain it at all, and vary in percentage even from sample to sample. Frequently the so-called CBD products are not containing any $\mathrm{CBD}$ at all, but mostly containing THC. This article is a systematic review of literature reviewing the available clinical data on $\mathrm{CBD}$, for use in various medical and psychiatric conditions with focus on a review of the pharmacology and toxicity. Resources used were ORVID, PubMed, MEDLINE, PsychINFO, EMBASE with keywords CBD, cannabidiol, hemp and cannabinoids.
\end{abstract}

Keywords: Cannabidiol; THC; Cannabis sativa

\section{Introduction}

$\mathrm{CBD}$, also called cannabidiol, is chemically derived from

Manuscript submitted April 9, 2020, accepted May 25, 2020

Published online June 25, 2020

aDepartment of Psychiatry, Western Psychiatric Hospital, University of Pittsburgh, UPMC Health, Pittsburgh, PA, USA

bDepartment of Psychiatry, Augusta University, Health Advocates PLLC, East Lansing, MI, USA

${ }^{\mathrm{c} C o r r e s p o n d i n g ~ A u t h o r: ~ T h e r s i l l a ~ O b e r b a r n s c h e i d t, ~ D e p a r t m e n t ~ o f ~ P s y c h i a t r y, ~}$ Western Psychiatric Hospital, University of Pittsburgh, UPMC Health, Pittsburgh, PA, USA. Email: Toberbarnscheidt@gmail.com

doi: https://doi.org/10.14740/jocmr4159 hemp (Cannabis sativa), which is the most commonly used illicit drug both nationally and internationally [1].

It was first obtained from American hemp and Egyptian hashish in 1940 [2]. In its natural form cannabis consists of the two most well-known active chemicals tetrahydrocannabinol (THC) and CBD as well as about 480 other active cannabinoids (CBs) that are not yet well researched. The THC in the cannabis is the psychoactive ingredient with toxicity. The THC content in a product labeled as CBD is supposed to contain less than $0.3 \%$ dry weight of THC in its leaves and buds [3].

Even though CBD use is a global problem, this article will focus on the current situation and trend within the US. Marijuana as well as CBD is purported for use in the US for the self-treatment of numerous medical and psychiatric conditions as a so-called "medicine". It is commonly used for depression, anxiety, seizures, nausea, appetite enhancer, anti-inflammatory, pain or the new trend to self-treat opioid use disorder [4].

Against the usual course of a medication development, both substances have not been scientifically investigated or developed prior to their use, but were determined by claims in the general public of their medicinal value [5]. Possible toxic effects and drug-drug interactions should be considered, and consumers should be educated about the risks and safety concerns regarding this substance, which are currently not publicized.

Due to CBD being exempt from federal regulations by the in 2018 passed US farm bill, it is easily accessible and available at convenience stores throughout the US [6].

The sale and marketing of CBD and CBD-containing products are very important economic factors as sales reached $\$ 2$ billion US dollars in 2018 and are rising [7].

Of the US population, $9 \%$ of the people less than 35 years of age reported the use of CBD at least once, $6.4 \%$ of the people between 45 and 55 years and $3.7 \%$ of the people over 55 years of age [8].

The question for public health is if CBD is really non-psychoactive and as safe as it is advertised in the general-public?

\section{Pharmacological Action of CBD}

$\mathrm{CBD}$ can be ingested in various routes. It is available in the form of oils, lotions, edibles, teas or smoked (Figs. 1, 2) [9]. It is rarely administered intravenously but that route is possible [10].

CBD undergoes a significant first pass metabolism in the liver after ingestion. The bioavailability after oral consumption 


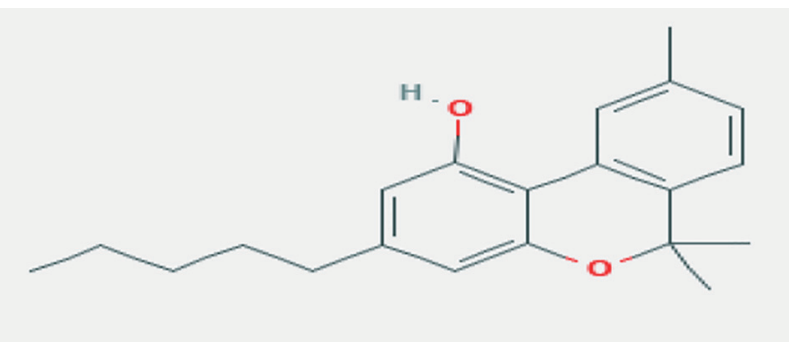

Figure 1. CBD chemical structure (source: PUBCHEM [9]). CBD: cannabidiol.

is estimated $6 \%$, and after smoking is estimated to be about $6-31 \%$ [11].

CBD's primary active metabolite is 7-hydroxy-CBD (7-OH-CBD) [12]. The half-life of CBD depends on the route of administration. Smoked, the half-life is about 27 - $35 \mathrm{~h}$, after oral ingestion 2 - 5 days and the shortest after intravenous injection with about $18-33 \mathrm{~h}$ [13].

CBD is very lipophilic, similar to cannabis, and easily passes the blood-brain barrier. It gets quickly distributed into adipose tissue and other organs. Due to its lipophilic quality, CBD accumulates in the adipose tissue particularly in patients with high adiposity and is redistributed into the circulation at a later point [14]. The amount used varies in a wide spectrum: administered doses in studies range from $5-1,500 \mathrm{mg} /$ day orally up to $30 \mathrm{mg}$ intravenously [15].

$\mathrm{CBD}$ does bind to the $\mathrm{CB}$ receptors, normally activated by endogenous $\mathrm{CBs}$ including anandamide and 2-arachidonylglycerol. There are two specific $\mathrm{CB}$ receptors identified. Unlike THC that binds to $\mathrm{CB} 1$ receptors that are mostly located in the brain, $\mathrm{CBD}$ binds mostly to $\mathrm{CB} 2$ receptors that are found on cells of the immune system, which include $\mathrm{T}$ and B lymphocytes, macrophages and monocytes which are not as highly expressed in the central nervous system [16].

The activation of those receptors decreases the release of neurotransmitters glutamate, gamma-aminobutyric acid (GABA), serotonin and norepinephrine and provides synaptic control of upstream neurotransmission [17-19].

CBD acts on several other receptor types. Those include receptors of the serotonin system $5 \mathrm{HT} 1 \mathrm{~A} / 2 \mathrm{~A} / 3 \mathrm{~A}$, glutamate, TRPV-a (vanilloid) receptors, agonist activity on alpha-1 adrenergic receptors as well as mu-opioid receptors [20].

In addition, CBD acts on the adenosine levels by reducing the adenosine reuptake, which has been associated with neuroprotection and anti-inflammatory processes in the brain [21].

CBD also acts directly on the cerebral vasculature by inhibiting the nitric oxide synthase protein expression as well as inhibition of calcium transport across membranes. Through this mechanism it causes vasodilatation [22].

$\mathrm{CBD}$ has shown in vitro studies to be a potent inhibitor with cytochrome P450 enzymes such as CYP1A2, CYP2B6, CYP2C9, CYP2D6 and CYP3A4 [23-36]. These enzymes are also responsible for the metabolization of various other medications. Therefore, CBD will most likely interfere with the serum levels of other medications such as antibiotics, antipsychotics, antidepressants and blood thinners as well as many more. Studies about these interactions are yet lacking. The in-

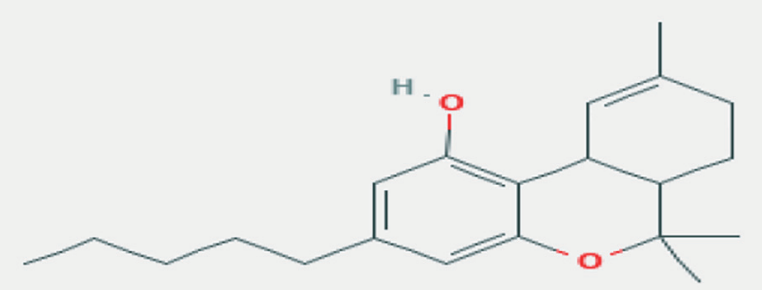

Figure 2. Chemical structure of THC for comparison (source: PUBCHEM [9]). THC: tetrahydrocannabinol.

teractions with CBD and other medications are summarized in Table 1 [23-36].

\section{Lethality Risk}

It is possible to ingest quantities of CBD that will cause a fatal overdose but very large doses are required for that to occur in human [36]. The toxicity levels for CBD can be found in the federal government's Toxicology Data Network [36]. The lethality risk with toxic substances is usually measured in the $\mathrm{LD}_{50}$ which is the amount of substance needed to kill $50 \%$ of the population [37].

There are three studies citied regarding the $\mathrm{LD}_{50}$ determination of CBD [37-12]: 1) In 1946, the $\mathrm{LD}_{50}$ for $\mathrm{CBD}$ in dogs was determined to be greater than $254 \mathrm{mg}$ per $\mathrm{kg}$ of body weight, when administered intravenously. 2) In 1975, an $\mathrm{LD}_{50}$ was established in mice at $50 \mathrm{mg}$ per $\mathrm{kg}$ of body weight, when administered intravenously. 3) In 1981, a report in Toxicology and Applied Pharmacology showed the $\mathrm{LD}_{50}$ for CBD to be $212 \mathrm{mg}$ per $\mathrm{kg}$ of body weight when administered intravenously in monkeys.

More recently, a 2011 article in the journal "Current Drug Safety" observed toxic levels of CBD in rhesus monkeys when administered orally. Doses over $200 \mathrm{mg}$ per $\mathrm{kg}$ of body weight proved to be fatal in some monkeys by way of respiratory arrest and cardiac failure, while $300 \mathrm{mg}$ per $\mathrm{kg}$ of body weight resulted in "rapid death" [12].

For reference, consider a relatively "average sized" human at $75 \mathrm{~kg}$ (approximately $165 \mathrm{lbs}$ ). By these numbers, it would take roughly $18,750 \mathrm{mg}(18.75 \mathrm{~g})$ of CBD consumed within a very short amount of time to result in any potentially fatal effects. By comparison, most typical CBD oil users consume no more than $100 \mathrm{mg}$ of the compound, and that is throughout the course of an entire day [41].

\section{CBD's Effect on Medical and Psychiatric Condi- tions}

Table $2[14,42-85]$ gives an overview of the toxic effects of CBD that are further discussed more in detail.

Some of the listed effects are more acute in nature, and others are more chronic.

Anaphylaxis and rashes are usually occurring immediately 
Table 1. CYP 450 Enzymes and Medication Interaction [23-36]

\begin{tabular}{|c|c|c|}
\hline Enzyme & Medication that interacts & Effect \\
\hline CYP3A4 substrate & $\begin{array}{l}\text { Immunosuppressants, antidepressants, opioids, statins, } \\
\text { benzodiazepines }\end{array}$ & Increases toxic effects/levels of substrate \\
\hline CYP3A4 inducer & $\begin{array}{l}\text { Phenytoin, topiramate, carbamazepine, rifampicin, efavirenz, } \\
\text { pioglitazone }\end{array}$ & $\begin{array}{l}\text { Decreases bioavailability of CBD } \\
\text { Reduces effect/level of CBD }\end{array}$ \\
\hline CYP2C19 substrate & $\begin{array}{l}\text { Proton pump inhibitor, antidepressants, antiepileptics, clopidogrel, } \\
\text { propranolol, warfarin, cyclophosphamide }\end{array}$ & Increases toxic effects/level of substrate \\
\hline CYP2C19 inhibitor & $\begin{array}{l}\text { Cimetidine, proton pump inhibitors, fluvoxamine, clopidogrel, } \\
\text { fluconazole }\end{array}$ & Increases level/toxicity of CBD \\
\hline CYP2C19 inducer & $\begin{array}{l}\text { Phenobarbital, phenytoin, St. John's Wort, rifampicin, } \\
\text { carbamazepine }\end{array}$ & $\begin{array}{l}\text { Decreases bioavailability of CBD } \\
\text { Reduces effect/level of CBD }\end{array}$ \\
\hline CYP2C $8 / 9$ & $\begin{array}{l}\text { Buprenorphine, montelukast, celecoxib, } \\
\text { phenobarbital, phenytoin, warfarin, valsartan }\end{array}$ & Increases toxic effects/levels of substrate \\
\hline
\end{tabular}

CBD: cannabidiol.

after ingestion. Also, dizziness as well as vomiting, diarrhea and dry mouth occur shortly after ingestion.

Depending on the route of ingestion, the toxic effects occur faster with increased bio-availability. The effects on mood and thoughts as well as sleep and immune-system will be discussed more in detail below. The toxic effects can occur even with very small doses of CBD depending on the user's sensitivity but are more like to occur in higher doses. Users with impaired liver function are at higher risk to experience toxic effects than healthy individuals. There are no data available yet to differentiate reliably between the risks of different age groups, gender or ethnicity.

\section{Anxiety/post-traumatic stress disorder (PTSD)}

Anxiety and PTSD are very common psychiatric disorders in the US and are associated with substance use. While cannabis with its THC content has shown to be anxiogenic during intoxication as well as withdrawal, CBD has been discussed to have some anxiolytic potential $[42,43]$.

In animal studies, the systemic administration of CBD had caused a decrease in neurons associated with fear (c-Fos positive neurons) and a direct infusion of CBD in the amygdala neurons has led to decreased anxiety-related behaviors [44]. Another animal model showed that CBD modifies the cerebral blood flow in brain areas that play a role in anxiety symptoms: amygdala, hippocampus, hypothalamus as well as cingulate cortex [45].

Several human studies have shown some positive results of CBD in anxiety conditions as well. The effect of CBD on the amygdala was studied in brain imaging studies and showed a decrease in activation in the amygdala after administration of CBD [46].

A placebo-controlled study by Crippa et al showed a decrease in social anxiety symptoms but also sedation in a small group of 10 patients receiving CBD. The patients in this clinical study were treatment naive and with 10 participants the study was small [47].

Another study by Bergamaschi among 24 treatment naive patients looked at the effect of $600 \mathrm{mg}$ CBD during a public speaking test and noticed a reduction in anxiety, cognitive impairment as well as discomfort in speech performance [48].

Furthermore, a study by Das et al including 48 healthy volunteers was evaluated for anxiety provoking electric shock anticipation and received either pure CBD without THC or placebo. The results showed that $\mathrm{CBD}$ increases extinction learning which might play a role in therapeutic approaches for anxiety disorder treatment [49].

The lifetime prevalence for PTSD in the US is about $6.1 \%$ of the population. The treatment has been mostly consistent of antidepressants as well as Prazosin for nightmares. CBD has been reported in case-control studies to be beneficial for nightmare symptoms associated with PTSD [50].

In another small study of 11 patients with PTSD, oral CBD was administered open-labeled and the patient's PTSD symptoms were evaluated initially and on consecutive days up to 8 weeks after utilizing the PCL-5 test and score. Ninety-one percent of the patients reported a decrease in nightmare symptoms. None of the patients reported side effects [51].

However, despite these studies with small patient numbers, utilizing the pure form of CBD, there are also several case reports of CBD-induced anxiety symptoms as a toxic side effect from the substance.

Table 2. List of Toxic Effects From CBD Use [14, 42-85]

\begin{tabular}{lllllll}
\hline Anxiety & Depression & Suicidal ideation & Psychosis & Sedation & Anaphylaxis & Rash \\
\hline Insomnia & Nausea & Diarrhea & Vomiting & Dry mouth & Dizziness & Infections/immunosuppression \\
\hline
\end{tabular}

CBD: cannabidiol. 


\section{Depression}

As part of CBD's ability to control the cerebral neurotransmission of serotonin and norepinephrine and its active binding to 5HT-1 A receptors [17], CBD is thought to also have an effect on depression. In addition, CBD stimulates the synaptic plasticity and neurogenesis which also plays a role in the development and treatment of depression [17-20].

Some animal models have shown some promising results. A mouse depression model showed significant antidepressantlike effect after administration of CBD. The animals showed increased engagement on pleasurable activities [53].

However, in humans, there are very limited studies available. In vitro, $\mathrm{CBD}$ is found to be a microglial stabilizer which is similar to the medication lithium which could be beneficial for depression and mood stabilization [54].

In humans, there are only few case studies published of individual patients with a history of depression who have previously been on traditional treatment with selective serotonin reuptake inhibitor (SSRI) who successfully tried CBD products and experienced a significant improvement in their depressive symptoms [55].

Caution with these studies is warranted. The studies are utilizing a controlled CBD form without any significant THC content, studies have small patient numbers and the follow-up windows are short. Major toxic effects have been reported with the use of CBD, being more depressed one of them and even suicidal ideations $[52,56]$.

The pack insert of the FDA approved form of CBD Epidiolex lists depression and suicidal ideation as a possible adverse reaction. In the largest placebo-controlled clinical trial among 27,863 patients treated with Epidiolex and 16,029 patients treated with placebo, the risk of suicidal ideations was increased 1 in every 530 patient and four suicides occurred in the Epidiolex treated group versus none in the placebo group [57].

There are no compatible data available comparing OTC $\mathrm{CBD}$ with placebo regarding increased risk of suicidality.

\section{Psychosis}

In studies using animal models for schizophrenia, CBD has shown to improve psychotic symptoms [58]. Zuardi et al looked at the effect of CBD on stereotypy induced by dopaminergic agonist in rodents and found that $\mathrm{CBD}$ decreased those similarly to haldol [59]. In a mice model, CBD was compared with haloperidol and clozapine and was found to be equivalent in inhibition of the hyperlocomotion induced by amphetamines and ketamines [60]. In comparison to the conventional medication haloperidol and clozapine, CBD did not induce any catatonia, not even in doses as high as $480 \mathrm{mg} / \mathrm{kg}$. Most commonly, doses of $120-240 \mathrm{mg} / \mathrm{kg}$ were needed to show any effect, which points to a lower potency of CBD [60].

There are very few and limited studies available in humans. Boggs et al looked at the effect of CBD at $600 \mathrm{mg}$ in schizophrenia and reported that the medication was well toler- ated and did not worsen mood or suicidality but was ineffective in treating cognitive impairment and other neuropsychiatric complications of schizophrenia [61].

Another double-blind, randomized clinical trial compared CBD with amisulpride and noted similar clinical improvement with less side effects [62]. In the study, 33 patients with schizophrenia were followed over a 4-week period and received either amisulpride or CBD. Both patient groups improved similarly utilizing the positive and negative syndrome scale (PANSS) score with some superiority in improvement of the negative symptoms in the CBD group [62].

Leweke et al conducted a study looking at the effect of $\mathrm{CBD}$ on visual hallucinations induced by nabilone in healthy volunteers. CBD showed to decrease the degree in visual hallucinations [63]. This study since it uses a synthetic form of THC to induce psychosis, as well as other research groups, has raised the questions if $\mathrm{CBD}$ might have antagonizing effects to the negative psychotropic effects of THC and might be potentially protective of the side effects of THC [64].

The study populations in these studies are mostly small and the follow-up is short or only monitored in a one-time event. The number of available studies is very limited, and mostly there are individual case reports published [61, 65-67].

\section{Alzheimer's disease (AD)}

CBD has some pharmacological characteristics that might point to be benefit in the treatment of AD. Libro at al showed that $\mathrm{CBD}$ is able to prevent the development of amyloid plaques in vitro. The group pre-treated a gingiva tissue sample with CBD and looked at the change in mesenchymal stem cells, meaning that it could possibly be beneficial in the treatment of AD. Also, CBD regulates the expression of GDK3b a central factor implemented in the molecular pathogenesis of $\mathrm{AD}$ [68].

In animal models, $\mathrm{CBD}$ has shown to prevent glutamateinduced excitotoxicity and to reduce inflammatory mediators and well as reduce lipid peroxidase. In addition, the active binding to CB2 receptors was causing a down-regulation in microglial activation in animal in vivo studies. In a mouse model with hippocampal gliosis induced by injection of human $A \beta$-fragment, $C B D$ inhibited the glial cell activation and proinflammatory mediator release in a dose-dependent manner.

In a rat model, CBD stimulated the hippocampal neurogenesis which would technically mean that $\mathrm{CBD}$ reverses the disease [69].

In case reports of traumatic brain injuries, $\mathrm{CBD}$ has been found to reduce brain damage after cerebral trauma by improving the metabolic activity [70]. Those findings have been confirmed in magnetic resonance imaging (MRI) and positron emission tomography (PET) studies. Studies are ongoing that evaluate this effect in persons with high risk concussion rates, for example, football players.

CBD has been frequently associated with the side effect of sedation which would be very negative in patients with $\mathrm{AD}$ and lead to other medical complications due to decreased activity in this elderly population. More studies need to be done to show efficacy of $\mathrm{CBD}$ in $\mathrm{AD}$ or other forms of dementia. 


\section{Epilepsy and seizures}

The use of CBD for the treatment of seizures has been researched since the 1970s. Overall the idea is to utilize CBD's effect on neuronal hyperactivity which means excessive neuronal firing as it occurs in seizure disorders [72]. The exact mechanism of CBD's action on epilepsy is unknown. In vitro, CBD has shown to decrease epileptiform local field potentials, their amplitude and duration [14].

In animal models, predominantly mice, it has shown some positive effects in few studies but no effect in most others. Studies performed in rats by Jones et al have shown anticonvulsant effects in partial pilocarpine and penicillin-induced seizures. In chronic epilepsy studies in animals have been less optimistic, showing little to no effect on the seizure activity [73].

In humans, the data are very limited for the natural form of CBD. The only FDA approved CBD medication for childhood seizures, Dravet and Lennox-Gastaut syndromes, is Epidiolex, which is a synthetic substance with a purity of $98 \% \mathrm{CBD}$ and less than $0.15 \%$ THC. Difference to the over-the-counter (OTC) CBDs is that Epidiolex is showing the same content of $\mathrm{CBD}$ and dose in one unit to the other. The two FDA approved conditions are both very severe and devastating forms of childhood seizures where seizures are most commonly refractory to traditional pharmaceutical treatment forms and children develop encephalopathy with intellectual disability and neurodevelopmental problems early on in their lives [74-77]. Epidiolex is an FDA approved medication, prescribed by physicians, and patients will be evaluated and monitored. In contrast this is not the case with the OTC form of CBD.

\section{Sleep}

Researches regarding the effect of CBD on sleep are still in its infancy. Endocannabinoids have been shown to play a role in the circadian rhythm, therefore CBD is thought to have an effect on sleep [78-80].

In animal models, studies have been performed to show the effect of CBD on the sleep quality as well as the sleep cycle [43]. In rats, studies have shown that high doses of CBD lead to increased total percentage of sleep. In another rodent model, high dose CBD led to increased rapid eye movement (REM) sleep latency, while the low dose CBD showed a decrease with no effect shown on the non-rapid eye movement (NREM) sleep [78].

Only few and small numbered human studies are available to show the effect of CBD on sleep. The sedating effect of CBD appears to be dose dependent. Low dose of CBD has been found to be more stimulating, while higher doses have a sedating effect. Two studies by Nicholson and Zuadi et al showed that a CBD dose of $160 \mathrm{mg} /$ day to increase sleep time in persons suffering insomnia as well as decrease nightly arousals while a lower dose again showed increased wakefulness [79, 80]. Basic research in humans showed an overall increase in the total amount of sleep with several sleep disorders $[79,80]$.

There are no data available yet to show the effects of CBD abstinence syndrome on sleep as it is described with THC to cause prolonged insomnia as a symptom or prolonged withdrawal [81]. Long-term and chronic use for insomnia bears the risk for development of dependence to CBD.

\section{Huntington's disease}

From pre-clinical studies, CBD is discussed to have protective effects against striatal degeneration [82]. In animal studies CBD has shown promising capabilities to reduce striatal dopamine hypersensitivity which is mediating chorea [83, 84]. This has been shown predominantly in rats. CBD also reduced the aggressive behaviors in rats treated with neurotoxin L-pyroglutamate which is one possible pathophysiological model for the aggressive behaviors seen in Huntington's disease [83].

A genetic mouse model has shown neuroprotective properties of CBD towards the striatal degeneration through selective binding to CB2 receptors [84].

Few clinical studies have looked at the effect of CBD on Huntington's disease and not shown beneficial value in the medicinal properties of CBD in the treatment of this devastating disease [85].

A study done by Consroe et al compared CBD versus placebo. The group used a mean dose of $700 \mathrm{mg}$ CBD daily on 15 patients with Huntington's disease. The group did not find any significant difference in chorea severity, side effects and lab tests after 6 weeks of treatment [85].

\section{Pain}

CBD is commonly used for pain without any scientific evidence nor FDA approval. Preclinical studies have proposed hat CBD might be useful in the treatment of chronic pain conditions [86].

However, clinical studies have been unconvincing so far. In Naftali's study, CBD at $10 \mathrm{mg}$ per day dose was shown ineffective in the treatment of Chron's disease [87]. Also, another study by Ben showed that CBD was ineffective at $40 \mathrm{mg}$ per day dose in the treatment of chronic neuropathic pain. Other people suggested CBD to be useful in the treatment of cancer pain but studies supporting this statement are yet to be done [88]. None of the available studies are long-term and showing relevant beneficial clinical effect to advocate for the use of $\mathrm{CBD}$ in pain conditions.

\section{Opioid use disorder (OUD)}

In the US approximately 2.5 million people have been diagnosed with an OUD and about 80 people each day die of overdose. OUD is a burden for each individual person, their families and the society. The annual costs associated with OUD are estimated 78 billon US dollars [1].

The conventional medication assisted treatments available for OUD including methadone, buprenorphine as well as naltrexone, have been of value but also associated with their own challenges. Those medications are regulated and require the 
person to be enrolled in a treatment program, which is timeconsuming and associated with a negative stigma. This bears grounds to investigate for alternatives, easier accessible and less controlled treatment options for OUD [89].

Blogs on the internet are attracting an increasing number of people with OUD and discuss the use of CBD during withdrawal as well as ongoing maintenance treatment. CBD is advertised as safe and with low lethality even in combination with strong opioid agonists [90].

In animal studies, CBD has been shown to reduce the rewarding effects of opioids and it also reduces the heroinseeking behaviors. CBD acts on the same receptors that heroin does and antagonizes the heroin's effect on CB1 and glutamate receptors [91].

The data from Colorado are concerning, with the increased use of CBs and THC, there has been a corresponding increase in opioid use and no decrease in opioid use since the legalization $[92,93]$.

However, there are only limited case reports available in humans regarding the use of CBD in OUD or small numbered clinical studies that are not allowing a broad statement regarding CBD's efficacy in the treatment of OUD.

The treatment of OUD with CBD bears particularly a risk, as the amount of CBD taken is not dosed in a controlled setting and for someone who has lost control over a substance prior might have difficulties dosing CBD as well.

\section{CBD and addiction}

$\mathrm{CBD}$ is unlike THC not binding to the cerebral $\mathrm{CB} 1$ receptor which is responsible for the rewarding effects of cannabis in its natural form and for the feeling of euphoria. Many articles state that CBD is a non-psycho-active substance [3-5]. However, it must have some degree of psycho-activity if it alters people's mood, anxiety as well as cognition.

As with many other substances listed in the DSM V for substance use disorders, it is also possible with CBD to experience a loss of control and a compulsive use. Even though the risk of lethality is very low, it does not mean it is impossible to become addicted to the substance $[37,38,94]$.

Withdrawal symptoms are not well described in the literature but however, most likely a person who takes CBD regularly for insomnia, will experience rebound insomnia if he stops [81].

Similar exacerbating effects are to be expected when CBD is no longer taken for depression or anxiety [12, 42]. Studies about the withdrawal symptoms from CBD and their course are yet to be published. Only case reports exist.

\section{Federal regulation}

Under Federal Law, marijuana is still listed as a schedule I substance which means that the substance is not accepted for medical use and has a high potential for abuse. In comparison, cocaine is a schedule II substance since it is used as an anesthetic medically [95].
The Drug Enforcement Administration (DEA) has specific criteria for a drug to be considered a medication [3, 6]: 1) The drugs chemistry must be known and reproducible; 2) The drug must have shown efficacy in well-controlled clinical study; 3 ) The drug must have shown safety; 4) It must be accepted by qualified experts and scientific evidence must be widely available.

CBD falls under the regulation of the "Farm Bill" (the agriculture improvement act of 2018, Pub. L. 115-334) which was signed in December 2018. This bill defines hemp as the cannabis plant, any part of it including extracts and cannabinoids with a THC concentration of less than $0.3 \%$ dry weight. "Hemp" was removed from the controlled substance act under federal law and is federally not considered a controlled substance $[95,96]$.

Especially problematic is the purity of the content that can be purchased currently. The requirements for quality control as well as labeling vary significantly from state to state. For example, California requires laboratory testing for medical and recreational cannabis and cannabis products while other states, for example, Arizona, do not mandate any laboratory testing $[97,98]$.

Over the last several years, including 2019, the FDA has issued several warning letters about unapproved new drugs on the market that allegedly contain CBD. The FDA had tested the content of these products and found a discrepancy of the claimed ingredients on the label and the actual content. Ninety percent of the tested $\mathrm{CBD}$ products contained much less $\mathrm{CBD}$ that what was posted on the label or no CBD at all, but the majority of tested products did contain a greater content of THC than claimed [99-103].

The FDA explicitly writes on their webpage that these products are not FDA approved for the diagnosis, cure, mitigation, treatment, or prevention of any disease and warns customers to beware purchasing or using any such products $[37,38]$.

The FDA further states that no food products can enter inter-state commerce and that CBD is not a safe food additive. $\mathrm{CBD}$ and other CBD or cannabis derived products should not be considered as dietary supplements as they contain pharmacologically active ingredients. Also, the FDA warns about the various dosing contents as there have been potentially toxic doses reported in certain food, for example, gummi bears containing $1,500 \mathrm{mg}$ of CBD $[37,38]$.

\section{Discussion}

The interest in cannabis products and CBD has exploded nationally over the last decade and the current trend is to legalize marijuana and make CBD available without strict regulations or control to the general public. CBD can nowadays be purchased online, in natural food stores, pet stores or retail outlet without a physician prescription despite claims for use in medical conditions.

Cannabis and CBD are almost seen as a "wonder drug" in the eye of the general public and claimed to help with conditions that are difficult to treat with established medications: AIDS, multiple sclerosis (MS), amyotrophic lateral sclerosis 
(ALS), Huntington's disease and might also mirror some mistrust and frustration in the medications that are currently available as FDA approved medications.

In the case of OUD treatment, people might try to use $\mathrm{CBD}$ to avoid being associated with the stigma of treatment for OUD. Buprenorphine and methadone clinics are still seen with some degree of negative stigma even amongst physicians. Affected people try to self-treat with other substances and consult blogs on the internet rather than professional treatment. There are also cases reported of CBD use for other use disorder for example alcohol or tobacco. The use of CBD in these cases bears the risk of potentially developing a new addiction or dependence in the process of substituting one drug with another. Data from Colorado since legalization are alarming and pointing to an increase of opioid use since the increased use of $\mathrm{CBs}$ and since legalization of marijuana. Well-established treatments for OUDs are available and should be preferred and advertised.

CBD might have some medicinal value, but main problem is that there is little established research nor control or regulation over the $\mathrm{CBD}$ product and people do not know what they are getting when they purchase CBD. CBD products vary highly in compositions and concentrations even from one unit to the other. The FDA issued warning letters about CBD products being falsely labeled and distributed.

The THC content is legally limited to be less than $0.3 \%$ but the reality shows that CBD products often contain higher amounts of THC and therefore the user gets put at risk to experience all the toxic side effects that are associated with marijuana and THC. The list of those toxic side effects includes attention-deficit/hyperactivity disorder (ADHD) like symptoms, cognitive impairment, aggression, behavior changes, paranoia, depression, anxiety, cancers and more.

The studies looking at the clinical effect of CBD on certain psychiatric and medical conditions utilize pure forms of CBD that had prior been tested of its contents for its ingredients and concentration, but this is not the form that the general public purchases in a convenience store.

The only form that is FDA approved CBD product that is considered a medication is the Epidiolex. The difference in calling it a "medication" is that one unit is consistent with the next and that it contains always the same dose. For OTC CBD this is not the case, the content varies as well as the psychoactive effect.

Given the inconsistency in the OTC CBD product, there are no dosing recommendations available for each claimed condition and they are not prescribed like a FDA approved medication and there is no physician follow-up.

Also, the use of CBD bears a risk for the user to develop toxic side effects from other medications that they are taking as prescribed as those might develop higher serum concentrations through the interaction of CBD with several CYP P 450 enzymes.

Persons with organ transplants are at risk of increased toxic effects from their immunosuppressant which might lead to organ failure, toxic levels of anticoagulants might lead to acute bleeding, and someone who is prescribed suboxone might experience sedation or respiratory depression even though he/she was previously on a stable dose.
After reviewing the literature, $\mathrm{CBD}$ is claimed as a psychoactive substance with effects on mood and behaviors and therefore bears the risk to develop an addiction.

Long-term studies in larger patient cohorts are needed to investigate the addictive potential of CBD.

\section{Conclusion}

More studies need to be done in humans in a controlled setting to determine the medicinal value of CBD for various diagnoses in order to be able to make clear recommendations.

Preclinical studies have shown some promising data regarding the medicinal value of CBD but studies in human are not consistent in outcome and controversial in their design. More studies need to be performed in human with larger sample sizes and longer follow-up periods.

Dosing guidelines for CBD need to be established for different indications and follow-up with a physician. The current situation, where the user does not know what they are actually getting in the product, makes CBD unsafe and the risk outweighs the benefit of recommending or using that substance. Especially the content of CBD needs to be under stricter regulations with lab monitoring to determine and guarantee a particular dose or content or CBD and to exclude a higher content of THC than the $0.3 \%$ that are allowed by law. Currently there is no consistency in the content of the CBD product.

It is dangerous to assume that the CBD is a "miracle drug" without any safety concerns given the list of potential toxic reactions. Particularly the sedating effect appears to be concerning and limiting in its use.

Cross-interactions with other medications need to be investigated to rule out toxicity in co-morbid patients taken numerous prescribed medications.

A possible development of an addictive disorder to CBD can from the current knowledge not be excluded and further data on long-term administration, the effects of tolerance and toxicity with administration of higher doses need to be investigated. From experience, if a substance is used over a prolonged period of time, there is a process of habituation involved and consecutively an increase in consumption of the substance.

Also, the claimed absence of psycho-active effects and absence of withdrawal symptoms upon discontinuation of CBD is from current point of view, subject to speculation.

The current trend of decriminalization of marijuana and its products bear the risk to further increase the CBD consumption with associated increase in health problems, violence, criminality and lethality.

\section{Acknowledgments}

None to declare.

\section{Financial Disclosure}

None to declare. 


\section{Conflict of Interest}

There is no conflict of interest.

\section{Author Contributions}

Thersilla Oberbarnscheidt contributed to the writing of article and literature research. Norman Miller contributed to research and editing of article.

\section{Data Availability}

The authors declare that data supporting the findings of this study are available within the article.

\section{References}

1. Office of the Surgeon General Facing Addiction in America: The Surgeon General's Report on Alcohol, Drugs, and Health. U.S. Department of Health and Human Services (HHS), Office of the Surgeon General; 2016.

2. FDA 2016. Botanical drug development guidance for industry. Available at: https://www.fda.gov/downloads/ Drugs/Guidances/UCM458484.pdf.

3. Grotenhermen F, Russo E. Cannabis and Cannabinoids: pharmacology, toxicology, and therapeutic potential. New York: Haworth press Inc; 2008.

4. Devinsky O, Cilio MR, Cross H, Fernandez-Ruiz J, French J, Hill C, Katz R, et al. Cannabidiol: pharmacology and potential therapeutic role in epilepsy and other neuropsychiatric disorders. Epilepsia. 2014;55(6):791802.

5. Zhornitsky S, Potvin S. Cannabidiol in humans-the quest for therapeutic targets. Pharmaceuticals (Basel). 2012;5(5):529-552.

6. https://www.federalregister.gov/documents/2016/12/14/2 016-29941/ establishment-of-a-new-drug-code-for-marih uana-extract.

7. Azer V, et al. Cowen's collective view of CBD. Cowen's Research. Available online: https://www.cowen.com/reports/cowen-collective-view-of-cbd/.

8. Bonaccorso S, Ricciardi A, Zangani C, Chiappini S, Schifano F. Cannabidiol (CBD) use in psychiatric disorders: a systematic review. Neurotoxicology. 2019;74:282-298.

9. Gaoni Y, Hashish MR. VII The isomerization of cannabidiol to tetrahydrocannabinols. Tetrahedron. 1996;22(4).

10. Lafaye G, Karila L, Blecha L, Benyamina A. Cannabis, cannabinoids, and health. Dialogues Clin Neurosci. 2017;19(3):309-316.

11. Agurell S, Halldin M, Lindgren JE, Ohlsson A, Widman M, Gillespie H, Hollister L. Pharmacokinetics and metabolism of delta 1-tetrahydrocannabinol and other cannabinoids with emphasis on man. Pharmacol Rev. 1986;38(1):21-43.

12. Bergamaschi MM, Queiroz RH, Zuardi AW, Crippa JA.
Safety and side effects of cannabidiol, a Cannabis sativa constituent. Curr Drug Saf. 2011;6(4):237-249.

13. Guy GW, Whittle BA, Robson P. The Medicinal uses of cannabis and cannabinoids. TJ International: Cronwall, UK. 2004.

14. Cunha JM, Carlini EA, Pereira AE, Ramos OL, Pimentel C, Gagliardi R, Sanvito WL, et al. Chronic administration of cannabidiol to healthy volunteers and epileptic patients. Pharmacology. 1980;21(3):175-185.

15. Rabgay K, Waranuch N, Chaiyakunapruk N, Sawangjit R, Ingkaninan K, Dilokthornsakul P. The effects of cannabis, cannabinoids, and their administration routes on pain control efficacy and safety: A systematic review and network meta-analysis. J Am Pharm Assoc (2003). 2020;60(1):225-234 e226.

16. Pertwee RG. The diverse $\mathrm{CB} 1$ and $\mathrm{CB} 2$ receptor pharmacology of three plant cannabinoids: delta9-tetrahydrocannabinol, cannabidiol and delta9-tetrahydrocannabivarin. Br J Pharmacol. 2008;153(2):199-215.

17. Russo EB, Burnett A, Hall B, Parker KK. Agonistic properties of cannabidiol at 5-HT1a receptors. Neurochem Res. 2005;30(8):1037-1043.

18. Pertwee RG, Ross RA, Craib SJ, Thomas A. -)-Cannabidiol antagonizes cannabinoid receptor agonists and noradrenaline in the mouse vas deferens. Eur J Pharmacol. 2002;456(1-3):99-106.

19. Bisogno T, Hanus L, De Petrocellis L, Tchilibon S, Ponde DE, Brandi I, Moriello AS, et al. Molecular targets for cannabidiol and its synthetic analogues: effect on vanilloid VR1 receptors and on the cellular uptake and enzymatic hydrolysis of anandamide. Br J Pharmacol. 2001;134(4):845-852.

20. De Petrocellis L, Ligresti A, Moriello AS, Allara M, Bisogno T, Petrosino S, Stott CG, et al. Effects of cannabinoids and cannabinoid-enriched Cannabis extracts on TRP channels and endocannabinoid metabolic enzymes. Br J Pharmacol. 2011;163(7):1479-1494.

21. Ross HR, Napier I, Connor M. Inhibition of recombinant human T-type calcium channels by Delta9tetrahydrocannabinol and cannabidiol. J Biol Chem. 2008;283(23):16124-16134.

22. Ahrens J, Demir R, Leuwer M, de la Roche J, Krampfl K, Foadi N, Karst M, et al. The nonpsychotropic cannabinoid cannabidiol modulates and directly activates alpha-1 and alpha-1-Beta glycine receptor function. Pharmacology. 2009;83(4):217-222.

23. Brown AJ. Novel cannabinoid receptors. Br J Pharmacol. 2007;152(5):567-575.

24. Zanger UM, Schwab M. Cytochrome P450 enzymes in drug metabolism: regulation of gene expression, enzyme activities, and impact of genetic variation. Pharmacol Ther. 2013;138(1):103-141.

25. Stott C, White L, Wright S, Wilbraham D, Guy G. A Phase I, open-label, randomized, crossover study in three parallel groups to evaluate the effect of Rifampicin, Ketoconazole, and Omeprazole on the pharmacokinetics of THC/ CBD oromucosal spray in healthy volunteers. Springerplus. 2013;2(1):236.

26. Geffrey AL, Pollack SF, Bruno PL, Thiele EA. Drug-drug 
interaction between clobazam and cannabidiol in children with refractory epilepsy. Epilepsia. 2015;56(8):12461251.

27. Gaston TE, Bebin EM, Cutter GR, Liu Y, Szaflarski JP, Program UC. Interactions between cannabidiol and commonly used antiepileptic drugs. Epilepsia. 2017;58(9):1586-1592.

28. Jiang R, Yamaori S, Okamoto Y, Yamamoto I, Watanabe $\mathrm{K}$. Cannabidiol is a potent inhibitor of the catalytic activity of cytochrome P450 2C19. Drug Metab Pharmacokinet. 2013;28(4):332-338.

29. Yamaori S, Okamoto Y, Yamamoto I, Watanabe K. Cannabidiol, a major phytocannabinoid, as a potent atypical inhibitor for CYP2D6. Drug Metab Dispos. 2011;39(11):2049-2056.

30. Yamaori S, Kushihara M, Yamamoto I, Watanabe K. Characterization of major phytocannabinoids, cannabidiol and cannabinol, as isoform-selective and potent inhibitors of human CYP1 enzymes. Biochem Pharmacol. 2010;79(11):1691-1698.

31. Yamaori S, Okushima Y, Yamamoto I, Watanabe K. Characterization of the structural determinants required for potent mechanism-based inhibition of human cytochrome P450 1A1 by cannabidiol. Chem Biol Interact. 2014;215:62-68.

32. Yamaori S, Koeda K, Kushihara M, Hada Y, Yamamoto I, Watanabe K. Comparison in the in vitro inhibitory effects of major phytocannabinoids and polycyclic aromatic hydrocarbons contained in marijuana smoke on cytochrome P450 2C9 activity. Drug Metab Pharmacokinet. 2012;27(3):294-300.

33. Yamaori S, Ebisawa J, Okushima Y, Yamamoto I, Watanabe K. Potent inhibition of human cytochrome P450 3A isoforms by cannabidiol: role of phenolic hydroxyl groups in the resorcinol moiety. Life Sci. 2011;88(1516):730-736.

34. Arnold WR, Weigle AT, Das A. Cross-talk of cannabinoid and endocannabinoid metabolism is mediated via human cardiac CYP2J2. J Inorg Biochem. 2018;184:88-99.

35. Zhou ZW, Chen XW, Sneed KB, Yang YX, Zhang X, He ZX, Chow K, et al. Clinical association between pharmacogenomics and adverse drug reactions. Drugs. 2015;75(6):589-631.

36. Van Driest SL, Shi Y, Bowton EA, Schildcrout JS, Peterson JF, Pulley J, Denny JC, et al. Clinically actionable genotypes among 10,000 patients with preemptive pharmacogenomic testing. Clin Pharmacol Ther. 2014;95(4):423-431.

37. Federal Government Toxicology Data Network (https:// toxnet.nlm.nih.gov).

38. Current Drug Safety. https://www.medicinalgenomics. com/wpcontent/uploads/2013/01/Bergamaschi_2011.pdf.

39. WHO. CANNABIDIOL (CBD). Critical review report. Expert Committee on Drug Dependence Fortieth Meeting. Geneva, June 4-7, 2018.

40. Ibeas Bih C, Chen T, Nunn AV, Bazelot M, Dallas M, Whalley BJ. Molecular Targets of Cannabidiol in Neurological Disorders. Neurotherapeutics. 2015;12(4):699730.
41. Iffland K, Grotenhermen F. An update on safety and side effects of cannabidiol: a review of clinical data and relevant animal studies. Cannabis Cannabinoid Res. 2017;2(1):139-154.

42. Blessing EM, Steenkamp MM, Manzanares J, Marmar CR. Cannabidiol as a potential treatment for anxiety disorders. Neurotherapeutics. 2015;12(4):825-836.

43. Hsiao YT, Yi PL, Li CL, Chang FC. Effect of cannabidiol on sleep disruption induced by the repeated combination tests consisting of open field and elevated plus-maze in rats. Neuropharmacology. 2012;62(1):373-384.

44. Zuardi AW, Cosme RA, Graeff FG, Guimaraes FS. Effects of ipsapirone and cannabidiol on human experimental anxiety. J Psychopharmacol. 1993;7(1 Suppl):82-88.

45. Crippa JA, Zuardi AW, Garrido GE, Wichert-Ana L, Guarnieri R, Ferrari L, Azevedo-Marques PM, et al. Effects of cannabidiol (CBD) on regional cerebral blood flow. Neuropsychopharmacology. 2004;29(2):417-426.

46. Fusar-Poli P, Crippa JA, Bhattacharyya S, Borgwardt SJ, Allen P, Martin-Santos R, Seal M, et al. Distinct effects of \{delta\}9-tetrahydrocannabinol and cannabidiol on neural activation during emotional processing. Arch Gen Psychiatry. 2009;66(1):95-105.

47. Crippa JA, Derenusson GN, Ferrari TB, Wichert-Ana L, Duran FL, Martin-Santos R, Simoes MV, et al. Neural basis of anxiolytic effects of cannabidiol (CBD) in generalized social anxiety disorder: a preliminary report. J Psychopharmacol. 2011;25(1):121-130.

48. Bergamaschi MM, Queiroz RH, Chagas MH, de Oliveira DC, De Martinis BS, Kapczinski F, Quevedo J, et al. Cannabidiol reduces the anxiety induced by simulated public speaking in treatment-naive social phobia patients. Neuropsychopharmacology. 2011;36(6):1219-1226.

49. Das RK, Kamboj SK, Ramadas M, Yogan K, Gupta V, Redman E, Curran HV, et al. Cannabidiol enhances consolidation of explicit fear extinction in humans. Psychopharmacology (Berl). 2013;226(4):781-792.

50. Zuardi AW, Shirakawa I, Finkelfarb E, Karniol IG. Action of cannabidiol on the anxiety and other effects produced by delta 9-THC in normal subjects. Psychopharmacology (Berl). 1982;76(3):245-250.

51. Campos AC, Guimaraes FS. Activation of 5HT1A receptors mediates the anxiolytic effects of cannabidiol in a PTSD model. Behav Pharmacol. 2009;(20):S54.

52. Brown JD, Winterstein AG. Potential adverse drug events and drug-drug interactions with medical and consumer cannabidiol (CBD) use. Journal of Clinical Medicine. 2019;(8):989.

53. Xu C, Chang T, Du Y, Yu C, Tan X, Li X. Pharmacokinetics of oral and intravenous cannabidiol and its antidepressant-like effects in chronic mild stress mouse model. Environ Toxicol Pharmacol. 2019;70:103202.

54. Rock EM, Bolognini D, Limebeer CL, Cascio MG, Anavi-Goffer S, Fletcher PJ, Mechoulam R, et al. Cannabidiol, a non-psychotropic component of cannabis, attenuates vomiting and nausea-like behaviour via indirect agonism of 5-HT(1A) somatodendritic autoreceptors in the dorsal raphe nucleus. Br J Pharmacol. 2012;165(8):2620-2634.

55. Hegazy O, Platnick H. Cannabidiol (CBD) for Treatment 
of Neurofibromatosis-related Pain and Concomitant Mood Disorder: A Case Report. Cureus. 2019;11(12):e6312.

56. van Ours JC, Williams J, Fergusson D, Horwood LJ. Cannabis use and suicidal ideation. J Health Econ. 2013;32(3):524-537.

57. EPIDIOLEX Cannabidiol prescribing Information. Available online at: https://www.epidiolex.com.

58. Rohleder C, Muller JK, Lange B, Leweke FM. Cannabidiol as a potential new type of an antipsychotic. a critical review of the evidence. Front Pharmacol. 2016;7:422.

59. Zuardi AW, Rodrigues JA, Cunha JM. Effects of cannabidiol in animal models predictive of antipsychotic activity. Psychopharmacology (Berl). 1991;104(2):260-264.

60. Moreira FA, Guimaraes FS. Cannabidiol inhibits the hyperlocomotion induced by psychotomimetic drugs in mice. Eur J Pharmacol. 2005;512(2-3):199-205.

61. Zuardi AW, Hallak JE, Dursun SM, Morais SL, Sanches RF, Musty RE, Crippa JA. Cannabidiol monotherapy for treatment-resistant schizophrenia. J Psychopharmacol. 2006;20(5):683-686.

62. Leweke FM, Koethe D, Gerth CW, et al. Cannabidiol as an antipsychotic. A double-blind, controlled clinical trial on cannabidiol vs amisulpride in acute schizophrenia. Eur Psychiatry. 2007;22:S14.02.

63. Leweke FM, Koethe D, Pahlisch F, Schreiber D, Gerth CW, Nolden BM, Klosterkotter J, et al. S39-02 Antipsychotic effects of cannabidiol. Eur. Psychiatry. 2009;24:S207.

64. Bhattacharyya S, Morrison PD, Fusar-Poli P, MartinSantos R, Borgwardt S, Winton-Brown T, Nosarti C, et al. Opposite effects of delta-9-tetrahydrocannabinol and cannabidiol on human brain function and psychopathology. Neuropsychopharmacology. 2010;35(3):764-774

65. Zuardi AW, Morais SL, Guimaraes FS, Mechoulam R. Antipsychotic effect of cannabidiol. J Clin Psychiatry. 1995;56(10):485-486.

66. Zuardi AW, Crippa JA, Hallak JE, Pinto JP, Chagas MH, Rodrigues GG, Dursun SM, et al. Cannabidiol for the treatment of psychosis in Parkinson's disease. J Psychopharmacol. 2009;23(8):979-983.

67. Hallak JE, Machado-de-Sousa JP, Crippa JA, Sanches RF, Trzesniak C, Chaves C, Bernardo SA, et al. Performance of schizophrenic patients in the Stroop Color Word Test and electrodermal responsiveness after acute administration of cannabidiol (CBD). Braz J Psychiatry. 2010;32(1):56-61.

68. Libro R, Diomede F, Scionti D, Piattelli A, Grassi G, Pollastro F, Bramanti P, et al. Cannabidiol modulates the expression of Alzheimer's disease-related genes in mesenchymal stem cells. Int J Mol Sci. 2016;18(1).

69. Wolf SA, Bick-Sander A, Fabel K, Leal-Galicia P, Tauber S, Ramirez-Rodriguez G, Muller A, et al. Cannabinoid receptor $\mathrm{CB} 1$ mediates baseline and activity-induced survival of new neurons in adult hippocampal neurogenesis. Cell Commun Signal. 2010;8:12.

70. Campos AC, Fogaca MV, Scarante FF, Joca SRL, Sales AJ, Gomes FV, Sonego AB, et al. Plastic and neuroprotective mechanisms involved in the therapeutic effects of cannabidiol in psychiatric disorders. Front Pharmacol.
2017;8:269.

71. Izquierdo I, Orsingher OA, Berardi AC. Effect of cannabidiol and of other cannabis sativa compounds on hippocampal seizure discharges. Psychopharmacologia. 1973;28(1):95-102.

72. Carlini EA, Leite JR, Tanhauser M, Berardi AC. Cannabidiol and Cannabis sativa extract protect mice and rats against convulsive agents. J Pharm Pharmacol. 1973;25:664-665

73. Do Val-da Silva RA, Peixoto-Santos JE, Kandratavicius L, De Ross JB, Esteves I, De Martinis BS, Alves MN, et al. Protective effects of cannabidiol against seizures and neuronal death in a rat model of mesial temporal lobe epilepsy. Front Pharmacol. 2017;8:131.

74. Devinsky O, Marsh E, Friedman D, Thiele E, Laux L, Sullivan J, Miller I, et al. Cannabidiol in patients with treatment-resistant epilepsy: an open-label interventional trial. Lancet Neurol. 2016;15(3):270-278.

75. Nabbout R, Thiele EA. The role of cannabinoids in epilepsy treatment: a critical review of efficacy results from clinical trials. Epileptic Disord. 2020;22(S1):23-28.

76. Devinsky O, Cross JH, Laux L, Marsh E, Miller I, Nabbout R, Scheffer IE, et al. Trial of cannabidiol for drugresistant seizures in the dravet syndrome. $\mathrm{N}$ Engl J Med. 2017;376(21):2011-2020

77. Thiele EA, Marsh ED, French JA, Mazurkiewicz-Beldzinska M, Benbadis SR, Joshi C, Lyons PD, et al. Cannabidiol in patients with seizures associated with Lennox-Gastaut syndrome (GWPCARE4): a randomised, double-blind, placebo-controlled phase 3 trial. Lancet. 2018;391(10125):1085-1096.

78. Chagas MH, Crippa JA, Zuardi AW, Hallak JE, Machadode-Sousa JP, Hirotsu C, Maia L, et al. Effects of acute systemic administration of cannabidiol on sleep-wake cycle in rats. J Psychopharmacol. 2013;27(3):312-316.

79. Nicholson AN, Turner C, Stone BM, Robson PJ. Effect of Delta-9-tetrahydrocannabinol and cannabidiol on nocturnal sleep and early-morning behavior in young adults. J Clin Psychopharmacol. 2004;24(3):305-313.

80. Zuardi AW. Cannabidiol: from an inactive cannabinoid to a drug with wide spectrum of action. Braz J Psychiatry. 2008;30(3):271-280.

81. Budney AJ, Moore BA, Vandrey RG, Hughes JR. The time course and significance of cannabis withdrawal. J Abnorm Psychol. 2003;112(3):393-402.

82. Sagredo O, Pazos MR, Satta V, Ramos JA, Pertwee RG, Fernandez-Ruiz J. Neuroprotective effects of phytocannabinoid-based medicines in experimental models of Huntington's disease. J Neurosci Res. 2011;89(9):15091518.

83. Consroe P, Musty R, Conti L. Effects of cannabidiol in animal mdodels of neurologic dysfunction. An international research report. National campaign against drug abuse monograph series no.7. Canberra: Australian Government Publishing Service. 1988:147-152.

84. Campos AC, Ortega Z, Palazuelos J, Fogaca MV, Aguiar DC, Diaz-Alonso J, Ortega-Gutierrez S, et al. The anxiolytic effect of cannabidiol on chronically stressed mice depends on hippocampal neurogenesis: involvement of 
the endocannabinoid system. Int J Neuropsychopharmacol. 2013;16(6):1407-1419.

85. Consroe P, Laguna J, Allender J, Snider S, Stern L, Sandyk R, Kennedy K, et al. Controlled clinical trial of cannabidiol in Huntington's disease. Pharmacol Biochem Behav. 1991;40(3):701-708.

86. Ferguson G, Ware M. Review article: sleep, pain and cannabis. Journal of Sleep Disorders \& Therapy. 2015;4(2):191.

87. Naftali T, Bar-Lev Schleider L, Dotan I, Lansky EP, Sklerovsky Benjaminov F, Konikoff FM. Cannabis induces a clinical response in patients with Crohn's disease: a prospective placebo-controlled study. Clin Gastroenterol Hepatol. 2013;11(10):1276-1280 e1271.

88. Chakravarti B, Ravi J, Ganju RK. Cannabinoids as therapeutic agents in cancer: current status and future implications. Oncotarget. 2014;5(15):5852-5872.

89. https://store.samhsa.gov/system/files/pep15-fedguideotp. pdf. Federal guidelines for opioid treatment programs.

90. Wiese B, Wilson-Poe AR. Emerging Evidence for Cannabis' Role in Opioid Use Disorder. Cannabis Cannabinoid Res. 2018;3(1):179-189.

91. Katsidoni V, Anagnostou I, Panagis G. Cannabidiol inhibits the reward-facilitating effect of morphine: involvement of 5-HT1A receptors in the dorsal raphe nucleus. Addict Biol. 2013;18(2):286-296.

92. https://www.sos.state.co.us/pubs/info_center/laws/COConstitution/ColoradoConstitution.pdf. Article XVIII Section 14.

93. http://www.sos.state.co.us/CCR/NumericalCCRDocList.
do?deptID $=19 \&$ deptName $=200 \% 20$ Revenue\&agencyI $\mathrm{D}=185$ \&agencyName $=212 \%$ A0Marijuana $\% 20$ Enforcement\%20Division.

94. Schoedel KA, Szeto I, Setnik B, Sellers EM, LevyCooperman N, Mills C, Etges T, et al. Abuse potential assessment of cannabidiol (CBD) in recreational polydrug users: A randomized, double-blind, controlled trial. Epilepsy Behav. 2018;88:162-171.

95. https://www.federalregister.gov/documents/2016/12/14/2 016-29941/establishment-of-a-new-drug-code-for-marih uana-extract. Accessed on April 22, 2018.

96. Bonn-Miller MO, Loflin MJE, Thomas BF, Marcu JP, Hyke T, Vandrey R. Labeling accuracy of cannabidiol extracts sold online. JAMA. 2017;318(17):1708-1709.

97. https://www.sos.state.co.us/pubs/info_center/laws/COConstitution/ColoradoConstitution.pdf. Article XVIII, Section 16.

98. Cole JM. Memorandum for all United States Attorneys. Guidance Regarding Marijuana Enforcement, Office of the Deputy Attorney General, August 29, 2013.

99. https://www.fda.gov/ICECI/EnforcementActions/WarningLetters/2017/ucm583192.htm.

100. https://www.fda.gov/ICECI/EnforcementActions/WarningLetters/2017/ucm583197.htm.

101. https://www.fda.gov/ICECI/EnforcementActions/WarningLetters/2017/ucm583205.htm.

102. https://www.fda.gov/ICECI/EnforcementActions/WarningLetters/2017/ucm583188.htm.

103. http://www.denvergov.org/content/dam/denvergov/Portals/771/documents/PHI/Food/CBDdocument.pdf. 